\title{
Characteristics and Outcomes of Frail Patients Hospitalised with Cardiovascular Diseases
}

\author{
(D) Tanissia Boukertouta1, (1) Sonia MSadek1, (1) François-Xavier Goudot'1, (D) Nabila Guendouze1, (1) Georges Sebbane2, \\ (D) Charlotte Cohen 1 , (D) Edith Martins-Meune ${ }^{3}$, (D) Samir Tine22, (D) Christophe Meune1,4 \\ ${ }^{1}$ Avicenne Hospital, Clinic of Cardiology, Bobigny, France \\ ${ }^{2}$ Avicenne Hospital, Clinic of Gerontology, Bobigny, France \\ 33Nanterre Hospital, Clinic of Gerontology, Naterre, France \\ 4 Inserm UMR S-942, Paris, France
}

\section{Abstract}

Objective: Frailty, a pre-disability state, is highly prevalent in older patients and negatively affects prognosis during or after hospitalisation. We examined the factors associated with a frailty index and this index's prognostic significance in a patient cohort with cardiovascular disease.

Materials and Methods: In this prospective study, patients aged $\geq 65$ years were admitted to a cardiology department for acutely decompensated cardiovascular diseases. The identification of seniors at risk-hospitalised patients (ISAR-HP) score was measured at admission, and two threshold values ( $\geq 2$ and $\geq 4$ ) were considered to define high-risk patients. Other variables included physical examination, laboratory testing, electrocardiogram, echocardiography, final diagnosis, course of hospitalisation and one-year mortality.

Results: We enrolled 166 patients with a mean age of $79.2 \pm 7.6$ years, and $51.2 \%$ of them were males. The main final primary diagnoses were as follows: $38.1 \%$ had acute heart failure, $15.1 \%$ supra-ventricular arrhythmias, $6.1 \%$ cardiac syncope, 5.4\% deep vein thrombosis/pulmonary embolism, 4.8\% acute coronary syndromes and 4.8\% acute hypertension. The ISAR-HP was measurable in 97\% of the cohort and identified 70.5\% and $32.5 \%$ of patients at high risk of further decline depending on the threshold value retained. Among the baseline characteristics and blood tests, advanced age, female gender, past or present heart failure, lower haemoglobin concentration, increased N-terminal pro-B-type natriuretic peptide concentration, increased troponin concentration and the need for oxygen support were associated with ISAR-HP $\geq 2$ ( $p<0.05$ for all). ISAR-HP scores of $\geq 2$ and $\geq 4$ were associated with a statistically significant seven-to-nine-fold increase in one-year mortality, respectively.

Conclusion: A high ISAR-HP $\geq 2$ score is prevalent in patients with cardiovascular disease and strongly affects one-year mortality. Age, past or present heart failure and increased cardiac biomarkers are the primary factors associated with a high ISAR-HP score.

Keywords: Ageing, frailty, cardiovascular diseases, heart failure

\section{Introduction}

With rises in life expectancy, increasing numbers of old patients are hospitalized in departments of cardiology. Mortality or functional decline are, unfortunately, very widespread outcomes after these patients are discharged, with an incidence ranging from 25\% to 59\% (1). Frailty is defined as an increased vulnerability to developing dependency when exposed to a stressor, such as hospitalization $(2,3)$. Frailty contributes to disease prognosis and negatively affects mortality in various conditions, including heart failure (HF) and acute coronary syndromes (ACS) (4-6). Frailty screening of aged patients is strongly recommended, and a comprehensive care plan should be implemented; this may include screening and treatment for sarcopenia and exhaustion, referral to a geriatrician, physical activity programs, nutritional supplementation, or social support programs (3).

Since the first description of physical frailty by Fried et al. (2), many frailty screening instruments have been developed, but consensus on which is optimal has not yet been reached $(6,7)$. In addition, these scales are rarely used in routine practice

Address for Correspondence: Christophe Meune, Avicenne Hospital, Clinic of Cardiology, Bobigny, France

Phone: +33 148955320 E-mail: christophe.meune@aphp.fr ORCID: orcid.org/0000-0002-8147-9265

Received: 10.06.2020 Accepted: 15.10.2020

Cite this article as: Boukertouta, MSadek S, Goudot FX, Guendouze N, Sebbane G, Cohen C, Martins-Meune E, Tine S, Meune C. Characteristics and Outcomes of Frail Patients Hospitalised with Cardiovascular Diseases. Eur J Geriatr Gerontol 2021;3(1):18-24

${ }^{\circ}$ Copyright 2021 by the Academic Geriatrics Society / European Journal of Geriatrics and Gerontology published by Galenos Publishing House. 
because they are time-consuming, and many non-geriatricians are unaware of the robustness of the scores obtained. However, the identification of seniors at risk-hospitalized patients (ISAR$\mathrm{HP}$ ) is a very simple scale that is based on four yes/no questions $(8,9)$. The sensitivity and specificity of the ISAR-HP score for predicting further decline were $87 \%$ and $39 \%$ in a study of patients hospitalized in the department of internal medicine, and $85 \%$ and $48 \%$ in a study of patients undergoing cardiac surgery, respectively $(8,9)$. To date, the ISAR-HP has mostly been studied in older patients admitted to departments of medicine, and little is known about its use in cardiology $(1,8)$. Our objectives were to measure the ISAR-HP scores of patients with various acute cardiovascular diseases, to determine the characteristics of patients with high ISAR-HP scores, and to examine its prognostic significance.

\section{Materials and Methods}

\section{Study design and population}

The SENIOR study is a prospective study that enrolled patients aged $\geq 65$ years who presented with any acute cardiovascular disease and were admitted to the department of cardiology of the university hospital of Avicenne from September 2017 to March 2018. Data on baseline characteristics, the results of laboratory testing, cardiac investigations, and mortality after discharge were collected. The exclusion criteria were as follows: death during the index period of hospitalization; transfer from or discharge to another department (except for rehabilitation); and inability to measure the ISAR-HP score (e.g., patients with mild/severe cognitive impairment who had no relatives present at admission, foreign patients who did not speak French or English, etc.). The study was approved by the local Ethics Committee, Comité de Protection des Personnes Ile de France III, and all patients granted their informed consent to participate in the study.

\section{Routine clinical assessment}

At admission, all patients underwent a physical examination and standard laboratory testing, including measurements of plasma high-sensitivity troponin $\mathrm{T}$ (hsTnT), N-terminal pro-B-type natriuretic peptide (NT-proBNP), and albumin concentration. They also underwent an electrocardiogram and echocardiography within 24 hours of admission. The necessity of other exams and aspects of patient management were at the discretion of the cardiologist and not specified by the study protocol.

\section{ISAR-HP determination}

The ISAR-HP score was determined by the admitting nurse present for each patient. In brief, the ISAR-HP is a scorecard with four yes/no questions on 1) needing assistance with instrumental activities of daily life (IADL), 2) the use of a walking device, 3) the need of assistance for travelling and 4) a low level of education. Each item is scored 0 or 1 except for the need for a walking device, which is scored as 0 or $2(8,9)$. Two threshold values have been proposed in the literature and were used in our study to define high-risk patients as scoring $\geq 2$ and $\geq 4$ (low risk if patients score 0 or 1, intermediate risk for 2 or 3 points, and high-risk for those who score 4-5 points) on the $\operatorname{ISAR-HP}(1,8,9)$.

\section{Follow-up}

All these data, as well as information about the course of hospitalization and final and associated diagnoses, were entered in a dedicated database. One-year mortality was determined by follow-up phone calls with the patients, their relatives and their physician if necessary. Follow-up information was entered in the database by the research nurse.

\section{Statistics}

The distribution of quantitative data was evaluated by histograms, coefficients of variation and a skewness and Kurtosis Normality test. Quantitative data are presented as means \pm standard deviation or medians (interquartile range) accordingly, qualitative data are presented as numbers (percentages) as appropriate.

The possible association between baseline characteristics and ISAR-HP $\geq 2$ scores was investigated using the Student's t-test, the Mann-Whitney U test, a chi-squared test, or Fisher's Exact test, as appropriate. A multivariate logistic regression was then applied, accepting all variables (from demographics, past medical history and treatments, baseline characteristics, screening blood tests, echocardiography and the final diagnosis) at $p<0.05$. The $\mathrm{R}$-squared value was 0.43 . A similar analysis was performed with the 3-category classification of the ISAR-HP (low, intermediate or high risk) using the Kruskal-Wallis Rank-sum test, the chisquared or Fisher's Exact test.

Time-to-death at 1 year is presented as Kaplan-Meier curves stratified according to the ISAR-HP score, comparisons between groups were performed with the Logrank test. Results are reported as relative risk (hazard ratios) with a respective confidence interval of $95 \%$. A $p$-value of $<0.05$ was considered significant. STATA statistical software (StataCorp, 2014) was used for all analyses.

\section{Results}

In total, 166 patients acutely hospitalized and discharged alive were included in the study. Five patients were not included in the study due to an incomplete ISAR-HP score because the level of education could not be ascertained. The mean age was $79.2 \pm 7.6$ years: $51.2 \%$ were male, $18.1 \%$ were living alone, and $7.1 \%$ were rest-home residents. The final diagnosis was acute 
HF in 38.0\% of patients, supra-ventricular arrhythmias in $15.1 \%$, conduction-disease related syncope in $6.1 \%$, deep vein thrombosis or pulmonary embolism in 5.4\%, non-ST segment elevation ACS in 4.8\%, the same as for acute hypertension and valvular disease, reflex and other causes of syncope in $4.2 \%$, specific cardiomyopathy in 3.6\%, acute pericarditis in 3.0\%, the same as for myocarditis, endocarditis in $2.4 \%$, ventricular arrhythmias in 1.8\%, pulmonary hypertension in 1.8\%, and chronic coronary syndrome in $1.2 \%$. It is noteworthy that $23.6 \%$ of patients had concomitant infectious disease (mostly upper respiratory tract infection).

The median duration of hospitalization was 5 (3-7) days, 80.7\% of patients were discharged home and 8.4\% needed additional home support at discharge. After discharge, 46.4\% visited their general practitioner within 1 month and only $16.9 \%$ visited a cardiologist within 1 month. Table 1 summarizes the main demographic and clinical characteristics of our cohort according to their ISAR-HP scores $(<2$ or $\geq 2$ ), and Table 2 presents the data collected during the hospitalization and the follow-up period. Seven patients (4.2\%) were lost to follow-up, including four patients who scored $<2$ and three patients who scored $\geq 2$; all of these patients were foreigners or homeless people. Mortality within 1 year occurred in 31/159 patients $(19.5 \%)$.

\section{ISAR-HP score and associated factors}

The ISAR-HP scores ranged from 0 to 5 (Figure 1); 105 (63.3\%) patients needed some help in IADL, 69 (41.6\%) used a walking device, 92 (55.4\%) needed help for travelling and 93 (56.0\%) had a low level of education. In all, 117 (70.5\%) patients scored $\geq 2 ; 29.5 \%, 38.0 \%$, and $32.5 \%$ of patients respectively were considered at low, intermediate and high risk of further decline according to the 3 -class risk stratification.

Patients who scored $\geq 2$ were older $(p<0.001)$, were more likely to have histories of chronic HF and were more often admitted for acute $\mathrm{HF}$, had increased systolic blood pressure, more frequently required oxygen support, had lower haemoglobin concentrations, increased NT-proBNP and hsTnT concentrations ( $p<0.05$ each) and a trend toward reduced albumin concentrations $(p=0.064)$. The length of hospitalization was on average one day longer in patients with ISAR-HP $\geq 2$ when compared to patients who scored $<2 \quad(p=0.027)$. We observed no significant differences in atherosclerosis risk factors, treatment at admission, mode of discharge, need for additional home support, or outpatient visits (Table 1, 2). In the multivariate analysis, age was the only factor independently associated with an ISAR-HP score of $\geq 2$. Analyses using the 3-class risk stratification of the ISAR-HP score and a threshold value of $\geq 4$ to define high-risk patients yielded similar results.

\section{The ISAR-HP score and one-year mortality}

Figure 2 shows that when compared to survivors, patients who died within one year of enrolment had higher ISAR-HP scores [2.0 (1-4) vs. 3.5 (2-4) respectively, $p=0.007$ ] and more often scored $\geq 2$ (64.3\% vs. $92.9 \%$ respectively, $p=0.003)$. Table 3 demonstrates that when compared to patients at low risk of future decline, those at high risk had a 7.2-fold risk of death at one year (if expressed as two categories, ISAR-HP $\geq 2$ vs. $<2$ ) or a 9.0-fold risk of death at one year (if expressed in three categories, low, intermediate and high risk). Similar results were found after excluding patients with acute HF (respective hazard ratios of 6.3 and 15.2).

\section{Discussion}

This prospective study measured the ISAR-HP scores for patients hospitalized in a department of cardiology for acute

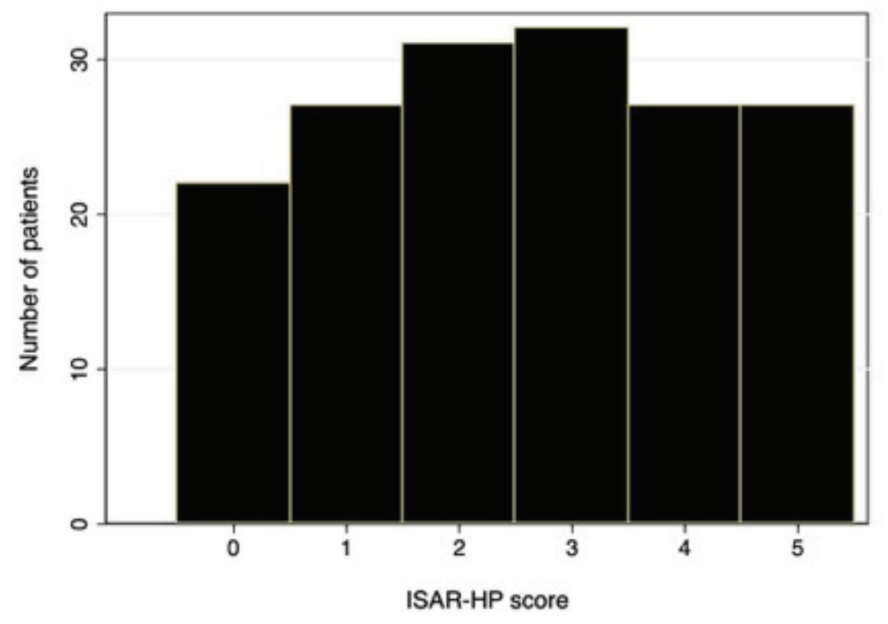

Figure 1. Distribution of the ISAR-HP score

ISAR-HP: Identification of seniors at risk-hospitalized patients

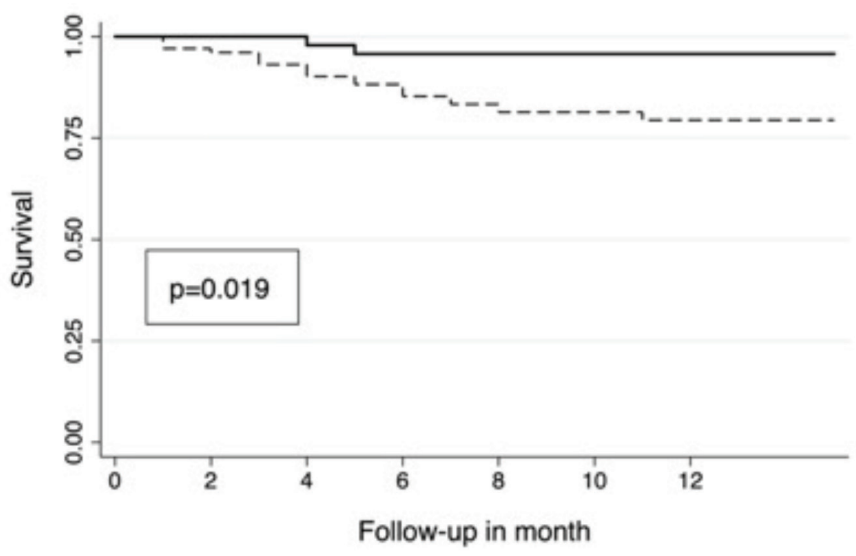

ISAR-HP $<2 \quad---\cdot \cdot$ ISAR-HP $>=2$

Figure 2. Kaplan Meier representation of one-year all-cause mortality in patients with and without increased ISAR-HP scores

ISAR-HP: Identification of seniors at risk-hospitalized patients 
cardiovascular disease. First, our results show that frailty is very widespread in patients with HF but also in those with other cardiovascular diseases. Second, it was feasible for the ISAR-HP scorecard to be assessed by a nurse in 5 minutes for almost all patients at presentation. Third, we found patients with ISARHP score $\geq 2$ to be older, with past and/or present HF, have a lower haemoglobin concentration and have more severe cardiac disease at presentation. Fourth, our results show that a high ISAR-HP score is associated with a seven-to-ninefold increase in one-year mortality.

Functional decline after hospitalization, known as frailty, is highly prevalent in aged patients possibly affecting between $30 \%$ and $60 \%$ of patients (10). Several frailty indexes have been developed and have demonstrated their capacity to predict decline as well as mortality $(1,2,4,10,11)$. Sokoreli et al. (12) reported that a clinical model including blood tests was less effective than a clinical model enriched by frailty indexes to predict death or re-admission in patients with HF; this suggests that frailty indexes should be part of the routine evaluation of these patients $(3,12)$. Very recently, Testa et al. (11) investigated a large cohort of old patients and reported that multidimensional frailty scores were more predictive of mortality than were physical scores, both in the absence of and even more in the presence of HF. However, the existence of multiple such risk scales and the absence of any consensus on the optimal one to perform, as well as the complexity of

Table 1. Patients' characteristics on admission

\begin{tabular}{|c|c|c|c|c|}
\hline Variable & $\begin{array}{l}\text { Total cohort } \\
(n=166)\end{array}$ & $\begin{array}{l}\text { ISAR-HP }<2 \\
(n=49)\end{array}$ & $\begin{array}{l}\text { ISAR-HP } \geq 2 \\
(n=117)\end{array}$ & $\mathbf{p}$ \\
\hline Age, years & $79.2 \pm 7.6$ & $74.5 \pm 6.6$ & $81.1 \pm 7.2$ & $p<0.001$ \\
\hline Male gender & $85(51.2 \%)$ & $32(65.3 \%)$ & $53(45.3 \%)$ & 0.019 \\
\hline Past CAD & $35(21.1 \%)$ & $9(18.4 \%)$ & $26(22.2 \%)$ & 0.579 \\
\hline Past CHF & $35(21.2 \%)$ & $5(10.2 \%)$ & $30(25.9 \%)$ & 0.025 \\
\hline Past arrhythmia & $51(30.7 \%)$ & $10(20.4 \%)$ & $41(35.0 \%)$ & 0.062 \\
\hline Diabetes & $67(40.4 \%)$ & $20(40.8 \%)$ & $47(40.2 \%)$ & 0.938 \\
\hline Hypertension & $122(73.5 \%)$ & $34(69.4 \%)$ & $88(75.2 \%)$ & 0.438 \\
\hline Current smoker & $4(2.4 \%)$ & $2(4.1 \%)$ & $2(1.7 \%)$ & 0.582 \\
\hline Hypercholesterolemia & $26(15.7 \%)$ & $8(16.3 \%)$ & $18(15.4 \%)$ & 0.879 \\
\hline Renal failure & $27(16.3 \%)$ & $5(10.2 \%)$ & $22(18.8 \%)$ & 0.171 \\
\hline Dementia & $16(9.6 \%)$ & $2(4.1 \%)$ & $14(12.0 \%)$ & 0.154 \\
\hline Married & $136(81.9 \%)$ & $42(85.7 \%)$ & $94(80.3 \%)$ & 0.412 \\
\hline $\begin{array}{l}\text { Drug regimen* } \\
\text { Aspirin } \\
\text { Anticoagulant } \\
\text { Beta-adrenergic blocker } \\
\text { Diuretics } \\
\text { ACE inhibitor/ARB } \\
\text { Statins }\end{array}$ & $\begin{array}{l}65(40.4 \%) \\
41(25.5 \%) \\
72(44.7 \%) \\
85(52.8 \%) \\
87(54.4 \%) \\
71(44.1 \%) \\
\end{array}$ & $\begin{array}{l}18(40.0 \%) \\
9(20.0 \%) \\
17(37.8 \%) \\
20(44.4 \%) \\
21(47.7 \%) \\
20(44.4 \%) \\
\end{array}$ & $\begin{array}{l}47(40.2 \%) \\
32(27.6 \%) \\
55(47.4 \%) \\
65(56.0 \%) \\
66(56.9 \%) \\
51(44.0 \%) \\
\end{array}$ & $\begin{array}{l}0.952 \\
0.321 \\
0.270 \\
0.186 \\
0.298 \\
0.956 \\
\end{array}$ \\
\hline Total number of treatments & $6.2 \pm 3.2$ & $5.9 \pm 3.6$ & $6.4 \pm 3.1$ & 0.455 \\
\hline $\begin{array}{l}\text { Clinical presentation } \\
\text { Heart rate, bpm } \\
\text { Systolic } \mathrm{BP}, \mathrm{mmHg} \\
\text { Diastolic } \mathrm{BP}, \mathrm{mmHg} \\
\text { Body temperature, }{ }^{\circ} \mathrm{C} \\
\text { Need of oxygen support, } \mathrm{n}\end{array}$ & $\begin{array}{l}77(65-94) \\
137(121-156) \\
70(62-83) \\
37.0(36.5-37.2) \\
32(19.3 \%)\end{array}$ & $\begin{array}{l}82(68-100) \\
132(116-150) \\
70(64-82) \\
36.8(36.5-37.0) \\
3(6.1 \%)\end{array}$ & $\begin{array}{l}73(65-90) \\
140(121-160) \\
70(62-90) \\
37.0(36.6-37.2) \\
29(24.8 \%)\end{array}$ & $\begin{array}{l}0.068 \\
0.046 \\
0.934 \\
0.283 \\
0.005 \\
\end{array}$ \\
\hline $\begin{array}{l}\text { Screening blood test } \\
\text { Hemoglobin, g/dL } \\
\text { Creatinine, } \mu \mathrm{mol} / \mathrm{L} \\
\text { NT-proBNP, pg/mL } \\
\text { Hs-TnT, ng/L } \\
\text { C-reactive protein, mg/L } \\
\text { Albumin, g/L }\end{array}$ & $\begin{array}{l}12.3(11.1-13.9) \\
97(75-126) \\
2.192(506-4.863) \\
26(16-47) \\
10(4-32) \\
33(31-36)\end{array}$ & $\begin{array}{l}12.8(11.8-14.6) \\
88(74-115) \\
1.605(137-3.800) \\
21(11-45) \\
7(2-17) \\
34(31-39) \\
\end{array}$ & $\begin{array}{l}12.1(11.0-13.7) \\
97(78-128) \\
2.409(921-7.896) \\
30(19-55) \\
12(5-45) \\
33(31-35)\end{array}$ & $\begin{array}{l}0.011 \\
0.283 \\
0.019 \\
0.037 \\
0.083 \\
0.064\end{array}$ \\
\hline
\end{tabular}




\begin{tabular}{|c|c|c|c|c|}
\hline & $\begin{array}{l}\text { Total cohort } \\
(n=166)\end{array}$ & $\begin{array}{l}\text { ISAR-HP }<2 \\
(n=49)\end{array}$ & $\begin{array}{l}\text { ISAR-HP } \geq 2 \\
(n=117)\end{array}$ & $\mathbf{p}$ \\
\hline LVEF, \% & $55(45-60)$ & $55(42-60)$ & $55(47-60)$ & 0.694 \\
\hline Length of hospitalization & $5(3-7)$ & $4(3-5)$ & $5(3-8)$ & 0.027 \\
\hline $\begin{array}{l}\text { Final diagnosis } \\
\text { Acute HF } \\
\text { Supra-ventricular arrhythmias } \\
\text { Conduction disease related syncope } \\
\text { DVT/PE } \\
\text { ACS }\end{array}$ & \begin{tabular}{|l}
$63(38.0 \%)$ \\
$25(15.1 \%)$ \\
$10(6.1 \%)$ \\
$9(5.4 \%)$ \\
$8(4.8 \%)$
\end{tabular} & $\begin{array}{l}13(26.5 \%) \\
9(18.4 \%) \\
3(6.1 \%) \\
3(6.1 \%) \\
3(6.1 \%)\end{array}$ & $\begin{array}{l}50(42.7 \%) \\
16(13.7 \%) \\
7(6.0 \%) \\
6(5.1 \%) \\
5(4.3 \%)\end{array}$ & $\begin{array}{l}0.045 \\
0.454 \\
0.983 \\
0.726 \\
0.696\end{array}$ \\
\hline Infectious disease & $39(23.6 \%)$ & $9(18.4 \%)$ & $30(25.9 \%)$ & 0.300 \\
\hline Total number of treatments at discharge & $7.1 \pm 3.3$ & $6.5 \pm 3.5$ & $7.4 \pm 3.2$ & 0.133 \\
\hline Discharge at home & $134(80.7 \%)$ & $44(89.8 \%)$ & $90(76.9 \%)$ & 0.083 \\
\hline Additional home support* & $14(8.4 \%)$ & $2(4.1 \%)$ & $12(10.3 \%)$ & 0.192 \\
\hline Outpatient visit by GP $<1$ mo & $77(46.4 \%)$ & $24(49.0 \%)$ & $53(45.3 \%)$ & 0.664 \\
\hline Outpatient visit by cardiologist $<1 \mathrm{mo}$ & $28(16.9 \%)$ & $8(16.3 \%)$ & $20(17.1 \%)$ & 0.904 \\
\hline
\end{tabular}

\begin{tabular}{|c|c|c|}
\hline Risk category & 12-months mortality & $\mathbf{p}$ \\
\hline $\begin{array}{l}\text { ISAR-HP }<2 \\
\text { ISAR-HP } \geq 2\end{array}$ & $\begin{array}{l}\text { Ref } \\
7.2(1.6-33.5)\end{array}$ & 0.003 \\
\hline $\begin{array}{l}\text { ISAR-HP low risk } \\
\text { ISAR-HP intermediate risk } \\
\text { ISAR-HP high risk }\end{array}$ & $\begin{array}{l}\text { Ref } \\
5.9(1.1-29.3) \\
9.0(1.7-46.6)\end{array}$ & $\begin{array}{l}0.014 \\
0.002\end{array}$ \\
\hline
\end{tabular}

administering many of these, have contributed to limiting their integration in clinical practice $(5,7,11)$.

The ISAR-HP score is one of the simpler frailty instruments. Although it has been less extensively studied than more complex tools, its prognostic significance has been demonstrated by findings from several cohorts of patients in emergency departments (EDs) $(6,13-15)$. Additionally, the ISAR-HP score has the theoretical advantage of being easily and rapidly assessed; this is confirmed by our study, as we report $97 \%$ of the scorecards were completed by a nurse within five minutes.

In our study, we measured the ISAR-HP score and fixed two distinct threshold values, $\geq 2$ or $\geq 4$ (1). We reported that $70.5 \%$ and $32.5 \%$ of patients respectively were at high risk, according to these criteria. This is consistent with the study of Buurman et al. (1), who used the same scale with identical threshold values and reported that $40 \%$ of patients were at high risk; however, only $4.3 \%$ of their patients were admitted for symptoms of cardiovascular disease. Our study also shows that more patients with ISAR-HP $\geq 2$ versus $<2$ had a final diagnosis of Acute HF (42.7\% vs. 26.5\% respectively, $p<0.05)$ as well as $\geq 4$ versus $<4$ ( $42.9 \%$ vs. $25.5 \%$ respectively, $\mathrm{p}<0.05)$. This is consistent with other studies that report a high proportion of frailty among patients with acute/chronic $\mathrm{HF}$, ranging from $30 \%$ to $56 \%$ depending on the assessment tool used $(5,11,16,17)$. Several hypotheses can be generated to explain such a high prevalence of frailty in HF patients. Both conditions share common aspects, including more advanced age (especially in HF with preserved ejection fraction), the presence of comorbidities, inflammation, and undernutrition and deficiencies $(4,11)$. This may also explain the increased risk of the incident of HF observed in frail patients (18).

The relationship between frailty and hospitalization is complex. On the one hand, frailty accentuates the risk of future decline after hospitalization, but on the other, it has been suggested that functional decline may even precede hospitalization and continues during hospitalization $(19,20)$. As we collected data at admission, our results cannot have been influenced by the course of hospitalization, but likewise cannot address any possible deterioration before the event.

Only a few studies have examined the clinical and biological factors associated with frailty. In our study, we collected demographic characteristics, past medical history and treatment, cardiac echo and biomarkers, general prognostic markers (e.g., renal function, risk factors, or comorbidities) and specific geriatric indexes (including the ISAR-HP score, albumin, and number of treatments at admission). We report that advanced age, female gender, past and/or present HF, lower haemoglobin concentration, increased NT-proBNP and troponin concentrations, and the need for oxygen support are all associated with a high ISAR-HP score.

Natriuretic peptides and troponins are well-known markers of acute HF and ACSs respectively, but have also been demonstrated to be related to the severity of 
various cardiovascular diseases and have high prognostic significance (21-23). Our results should be therefore interpreted as indicating increased frailty in older patients, female, HF patients and patients with more advanced cardiovascular disease. This is confirmed by the prolonged length of hospitalization we observed in patients with high ISAR-HP scores and is consistent with the few studies conducted previously $(5,10)$. In multivariate analysis, age was the only independent factor associated with an increased ISAR-HP score. This may be a consequence of the intrinsic characteristics of the ISAR-HP score, which focuses mainly on dependency rather than on physical activity. In addition, several variables included in the multivariable models are markers of the severity of the disease and correlate with each other.

We report that patients identified as high-risk by their ISARHP score have a 7- to 9-fold increase in one-year mortality, whether patients were admitted for acute HF or another cardiovascular disease. This extends the previous findings of worse outcomes observed in the ED and suggests that frailty should be considered a high-priority matter in cardiology $(1,15)$.

\section{Study Limitations}

Potential limitations of the current study merit consideration. First, more than $30 \%$ of our patients had a final diagnosis of $\mathrm{HF}$, which may have increased their ISAR-HP score and accounted for the increased mortality we observed. However, high oneyear mortality rates were observed in all patients with elevated ISAR-HP scores as well as in the subgroup of patients without acute $\mathrm{HF}$ as a final diagnosis.

Second, our study was performed in a single centre with a relatively limited number of patients. Third, only a few patients had known cognitive impairment. This may be explained by the fact that patients with dementia are more often hospitalized in geriatric units rather than in cardiology units.

Our study shows that frailty is very common in older patients with acute cardiac diseases and has a major impact on mortality. This suggests that frailty scales should be routinely measured in cardiology departments. The question of how to specifically manage these patients remains unsolved and cannot be derived from our study. Patient management may rely on programs incorporating systematic comprehensive geriatric assessment, rehabilitation, and/or nutritional support. Measurements provided by frailty indices may also enable clinicians to select the most cost-effective treatment strategies (24). This remains to be confirmed in dedicated studies.

\section{Conclusion}

The measurement of ISAR-HP scores is easily feasible in older patients hospitalized for cardiovascular disease. High ISAR-HP scores are associated with advanced age, severity of cardiac disease, and past or present HF. The scores aid the identification of patients at a high one-year risk of mortality.

\section{Acknowledgement}

The authors are indebted to the nurses who welcomed the patients and assessed the ISAR-HP scores.

\section{Ethics}

Ethics Committee Approval: The study was approved by the local Ethics Committee, Comité de Protection des Personnes Ile de France III.

Informed Consent: Informed consent to participate in the study.

Peer-review: Externally peer-reviewed.

\section{Authorship Contributions}

Surgical and Medical Practices: T.B., S.M.S., F-X.G., Concept: S.T., C.M., Design: G.S., S.T., C.M., Data Collection or Processing: N.G., Analysis or Interpretation: S.M.S., F-X.G., C.C., Literature Search: C.C., Writing: T.B., S.M.S., M.M.E., C.M.

Conflict of Interest: No conflict of interest was declared by the authors.

Financial Disclosure: The authors declared that this study sreceived no financial support.

\section{References}

1. Buurman BM, Hoogerduijn JG, van Gemert EA, de Haan RJ, Schuurmans MJ, de Rooij SE. Clinical characteristics and outcomes of hospitalized older patients with distinct risk profiles for functional decline: a prospective cohort study. PLoS One 2012;7:29621.

2. Fried $L P$, Tangen $C M$, Walston J, Newman $A B$, Hirsch $C$, Gottdiener J, Seeman T, Tracy R, Kop WJ, Burke G, McBurnie MA; Cardiovascular Health Study Collaborative Research Group. Frailty in older adults: evidence for a phenotype. J Gerontol A Biol Sci Med Sci 2001;56:146-156.

3. Dent $E$, Morley JE, Cruz-Jentoft $A J$, Woodhouse $L$, Rodríguez-Mañas $L$, Fried LP, Woo J, Aprahamian I, Sanford A, Lundy J, Landi F, Beilby J, Martin FC, Bauer JM, Ferrucci L, Merchant RA, Dong B, Arai H, Hoogendijk EO, Won CW, Abbatecola A, Cederholm T, Strandberg T, Gutiérrez Robledo LM, Flicker L, Bhasin S, Aubertin-Leheudre M, Bischoff-Ferrari HA, Guralnik JM, Muscedere J, Pahor M, Ruiz J, Negm AM, Reginster JY, Waters DL, Vellas B. Physical Frailty: ICFSR International Clinical Practice Guidelines for Identification and Management. J Nutr Health Aging 2019;23:771787.

4. Deniz A, Ozmen C, Bayram E, Seydaoglu G, Usal A. Frailty significantly impairs the short term prognosis in elderly patients with heart failure. J Geriatr Cardiol 2018;15:675-681.

5. Sze S, Pellicori P, Zhang J, Weston J, Clark AL. Identification of Frailty in Chronic Heart Failure. JACC Heart Fail 2019;7:291-302.

6. Man C, Xiang S, Fan Y. Frailty for predicting all-cause mortality in elderly acute coronary syndrome patients: A meta-analysis. Ageing Res Rev 2019;52:1-6.

7. McDonagh J, Martin L, Ferguson C, Jha SR, Macdonald PS, Davidson PM, Newton PJ. Frailty assessment instruments in heart failure: A systematic review. Eur J Cardiovasc Nurs 2018;17:23-35. 
8. Hoogerduijn JG, Buurman BM, Korevaar JC, Grobbee DE, de Rooij SE, Schuurmans MJ. The prediction of functional decline in older hospitalised patients. Age Ageing 2012;41:381-387.

9. Hoogerduijn JG, de Rooij SE, Grobbee DE, Schuurmans MJ. Predicting functional decline in older patients undergoing cardiac surgery. Age Ageing 2014;43:218-221.

10. Buurman BM, van Munster BC, Korevaar JC, de Haan RJ, de Rooij SE. Variability in measuring (instrumental) activities of daily living functioning and functional decline in hospitalized older medical patients: a systematic review. J Clin Epidemiol 2011;64:619-627.

11. Testa G, Curcio F, Liguori I, Basile C, Papillo M, Tocchetti CG, Galizia G, Della-Morte D, Gargiulo G, Cacciatore F, Bonaduce D, Abete P. Physical vs. multidimensional frailty in older adults with and without heart failure. ESC Heart Fail 2020;7:1371-1380.

12. Sokoreli I, Cleland JG, Pauws SC, Steyerberg EW, de Vries JJG, Riistama JM, Dobbs K, Bulemfu J, Clark AL. Added value of frailty and social support in predicting risk of 30-day unplanned re-admission or death for patients with heart failure: An analysis from OPERA-HF. Int J Cardiol 2019;278:167172 .

13. Afilalo J, Lauck S, Kim DH, Lefèvre T, Piazza N, Lachapelle K, Martucci G, Lamy A, Labinaz M, Peterson MD, Arora RC, Noiseux N, Rassi A, Palacios IF, Généreux P, Lindman BR, Asgar AW, Kim CA, Trnkus A, Morais JA, Langlois $Y$, Rudski LG, Morin JF, Popma JJ, Webb JG, Perrault LP. Frailty in Older Adults Undergoing Aortic Valve Replacement: The FRAILTY-AVR Study. J Am Coll Cardiol 2017;70:689-700

14. Carpenter CR, Shelton E, Fowler S, Suffoletto B, Platts-Mills TF, Rothman $R E$, Hogan TM. Risk factors and screening instruments to predict adverse outcomes for undifferentiated older emergency department patients: a systematic review and meta-analysis. Acad Emerg Med 2015;22:1-21.

15. de Gelder J, Haenen E, Lucke JA, Klop HG, Blomaard LC, Smit RAJ, Mesri K, de Groot B, Fogteloo AJ, Anten S, Blauw GJ, Mooijaart SP. Optimising the ISAR-HP to screen efficiently for functional decline in older patients. Neth J Med 2017;75:379-385.

16. Reeves GR, Whellan DJ, Patel MJ, O'Connor CM, Duncan P, Eggebeen JD, Morgan TM, Hewston LA, Pastva AM, Kitzman DW. Comparison of Frequency of Frailty and Severely Impaired Physical Function in Patients $\geq 60$ Years Hospitalized With Acute Decompensated Heart Failure Versus
Chronic Stable Heart Failure With Reduced and Preserved Left Ventricular Ejection Fraction. Am J Cardiol 2016;117:1953-1958.

17. Bell S, Dekker FW, Vadiveloo T, Marwick C, Deshmukh H, Donnan PT, Van Diepen M. Risk of postoperative acute kidney injury in patients undergoing orthopaedic surgery--development and validation of a risk score and effect of acute kidney injury on survival: observational cohort study. BMJ 2015;351:5639.

18. Khan $H$, Kalogeropoulos AP, Georgiopoulou $W$, Newman $A B$, Harris $T B$, Rodondi N, Bauer DC, Kritchevsky SB, Butler J. Frailty and risk for heart failure in older adults: the health, aging, and body composition study. Am Heart J 2013;166:887-894.

19. Covinsky KE, Palmer RM, Counsell SR, Pine ZM, Walter LC, Chren MM. Functional status before hospitalization in acutely ill older adults: validity and clinical importance of retrospective reports. J Am Geriatr Soc 2000;48:164-169.

20. De Saint-Hubert M, Schoevaerdts D, Cornette P, D'Hoore W, Boland B, Swine C. Predicting functional adverse outcomes in hospitalized older patients: a systematic review of screening tools. J Nutr Health Aging 2010;14:394-399.

21. Chenevier-Gobeaux C, Bonnefoy-Cudraz É, Charpentier S, Dehoux M, Lefevre G, Meune C, Ray P; SFBC, SFC, SFMU 'Troponins' workgroup. Highsensitivity cardiac troponin assays: answers to frequently asked questions. Arch Cardiovasc Dis 2015;108:132-149.

22. Januzzi JL Jr, Filippatos G, Nieminen M, Gheorghiade M. Troponin elevation in patients with heart failure: on behalf of the third Universal Definition of Myocardial Infarction Global Task Force: Heart Failure Section. Eur Heart J 2012;33:2265-2271.

23. Blankenberg $S$, Salomaa $V$, Makarova $N$, Ojeda $F$, Wild $P$, Lackner KJ, Jørgensen $T$, Thorand $B$, Peters $A$, Nauck $M$, Petersmann A, Vartiainen $E$, Veronesi G, Brambilla $P$, Costanzo S, lacoviello L, Linden G, Yarnell J, Patterson CC, Everett BM, Ridker PM, Kontto J, Schnabel RB, Koenig W, Kee $\mathrm{F}$, Zeller T, Kuulasmaa $\mathrm{K}$; BiomarCaRE Investigators. Troponin I and cardiovascular risk prediction in the general population: the BiomarCaRE consortium. Eur Heart J 2016;37:2428-2437.

24. Pulignano G, Del Sindaco D, Di Lenarda A, Tarantini L, Cioffi G, Gregori D, Tinti MD, Monzo L, Minardi G. Usefulness of frailty profile for targeting older heart failure patients in disease management programs: a costeffectiveness, pilot study. J Cardiovasc Med (Hagerstown) 2010;11:739-747. 